\title{
空間結合型マルチコアファイバ用接続部品
}

\author{
小林哲也, 渡辺正行, 鳥取裕作 \\ (株)オプトクエスト（テ362-0021 埼玉県上尾市原市1335番地）
}

\section{Space Coupling Optical Connecting Devices for Multicore Fibers}

\author{
Tetsuya KOBAYASHI, Masayuki WATANABE, and Yusaku TOTTORI \\ OPTOQUEST CO. LTD, 1335 Haraichi, Ageoshi, Saitama 362-0021
}

(Received January 23, 2013)

\begin{abstract}
Lens optics technology is reviewed for the design and fabrication of fan-in/fan-out devices to connect a multicore fiber to single mode fibers and optical connectors for multicore fibers. We describe the design principle of lens coupling using spatial beam conversion theory for fan-in/fan-out devices and multicore fiber connectors and show their optical characteristics. We also discuss the feasibility of the devices for multicore fiber transmission systems.
\end{abstract}

Key Words: Multicore fiber, Fan-in/Fan-out device, Connector, Lens optics coupling, Space division multiplexing

国内における通信トラフィックは，光ファイバを用い たブロードバンドサービスの急速な普及に伴い右肩上が りに増加を続けており, このまま増加が進めば通信容量 がいずれ逼迫すると言われている。

このような状況から2009年に独立行政法人情報通信研 究機構 (NICT) が中心となって「EXAT 構想が提唱され ${ }^{1}$, 「革新的光ファイバ技術の研究開発」により, 1本の光 ファイバに複数の伝搬コアを持つマルチコアファイバ (MCF)が開発された。

さらに2011年度からは「革新的光通信インフラの研究 開発」が開始され，2012年9月には，12コアMCF-52 kmを 用いて $1.01 \mathrm{~Pb} / \mathrm{s}$ の大容量伝送を実現し ${ }^{2)}$, 長距離伝送に 関しても7コアMCFとマルチコア光増幅器を用いた $6,160 \mathrm{~km}$ の長距離伝送実験 ${ }^{3)}$ 報告されている.

しかし，飛躍的に伝送容量を増大させることが可能な MCFを用いた伝送においても，MCF各コアへの信号入 出力を行う為には，MCFとシングルモードファイバ (SMF) とを接続するファンイン/ファンアウト $(\mathrm{FI} / \mathrm{FO})$ デ バイス，MCF同士を接続するMCFコネクタ技術が不可 欠である。

本稿では，これら MCFのFI/FO接続技術，MCFコネク 夕接続技術について，特に空間レンズ結合を用いた技術 について解説する。

$$
\begin{aligned}
& 2.1 \text { ファンイン/ファンアウトデバイスの原理 } \\
& \mathrm{MCF} \text { のアピッチは } 30 \sim 60 \mu \mathrm{m} \text { の間でコア間クロス }
\end{aligned}
$$
トークやファイバの曲げ等による特性劣化に配慮して設 計されている ${ }^{4,5)}$. 一方, 一般的に使用されているSMF

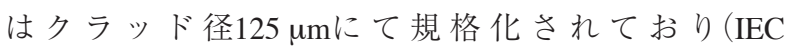
60793-2-50)，単純にSMFを束ねるだけではMCFとの接 続は出来ない(Fig. 1). そこでSMFをMCFコアピッチと 同径に細径加工後にバンドル化し，MCFと接続する方 式が検討されている ${ }^{6,7)}$. この方式は部品点数も少なく 有望な方式ではあるが，1 $\mu \mathrm{m}$ 以下の高精度なファイバ 外径加工を必要とし， かつSMFを細径化することでク ラッド層が薄くなることによる光学的, 機械的な悪影響 がないか検討が必要である。また，MCFのコアピッチ が変わるたびにSMFの細径加工条件を見直す必要もあ る.

本稿のように，空間光学系を利用すればSMF自体の加 工を行わずにMCFと接続することが可能となるととも

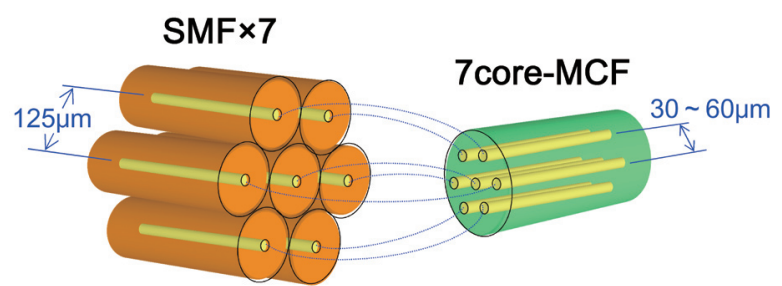

Fig. 1 Direct connection of 7 core MCF to SMFs. 


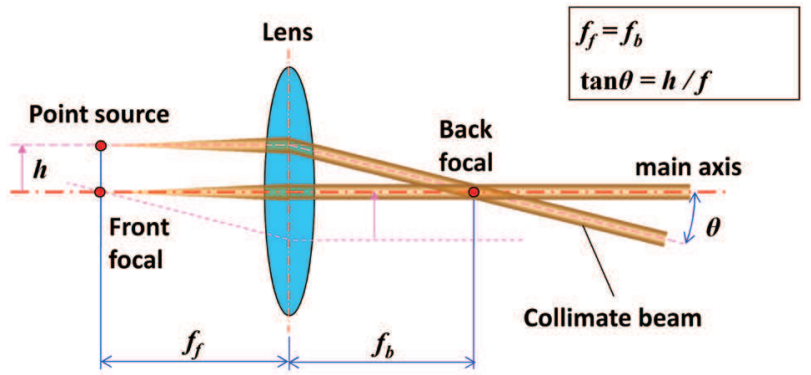

Fig. 2 Geometrical optics ray diagram of single lens.

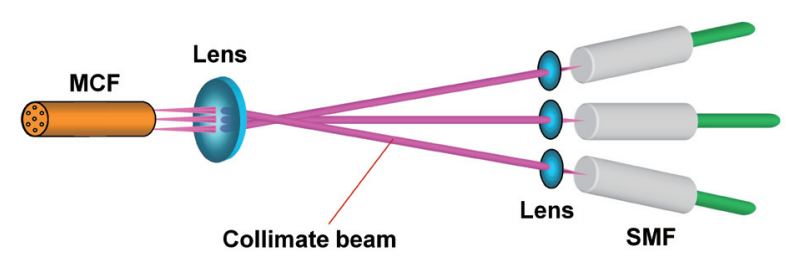

Fig. 3 Principle of lens coupling of MCF to SMFs.

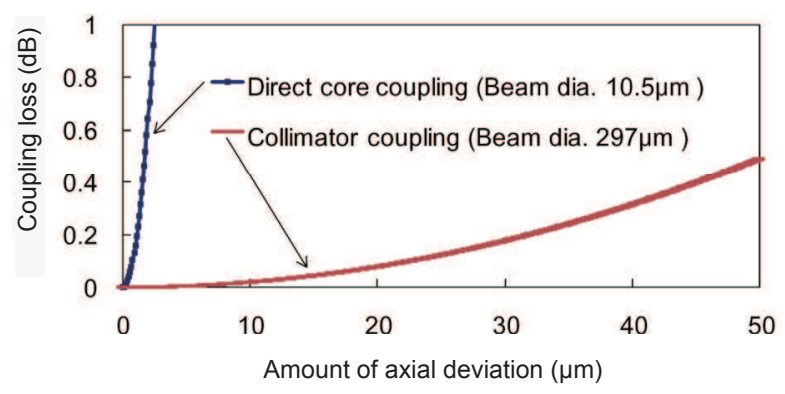

Fig. 4 Comparison of coupling loss tolerance to the axial deviation between direct core coupling (MFD: $10.5 \mu \mathrm{m})$ and collimator coupling.

に, MCFのコアピッチやコア数が変わった場合でも対 応することが出来る。以下にレンズを用いたMCFと SMFの空間結合原理について説明する.

Fig. 2は一般的な単レンズの幾何光学光線図を示した ものである。主軸上のレンズ前側焦点位置 $f_{f}$ に配置され た点光源より出射された光はレンズを通過し, 主軸と平 行なコリメート光として進む. 一方, 主軸からhの高さ でオフセットされた点光源からの光はレンズを通過する ことでコリメート光となり, レンズ後側焦点位置 $f_{b}$ を通 り, 角度 $\theta$ で進む。

この原理を用いて点光源を $\mathrm{MCF}$ 各コアと置き換える ことでMCF各コアの光を, 角度を持ったコリメート光 として分離させることが出来る. 分離されたコリメート 光をFig. 3のように単レンズにより集光させ, SMFのコ アに結合させることで, MCFとSMFとの空間結合を実 現できる，空間結合の利点は, $\phi 10 \mu \mathrm{m}$ 程度のコアから の光が, 焦点距離数mmのレンズを用いた場合 $\phi$ 数百 $\mu \mathrm{m}$ まで拡大されるため, Fig. 4に示すように, ファイバ直 接接続に比べ, 位置ずれに対する損失劣化を格段に緩和 できる。

\section{$2.2 \mathrm{MCF}$ コネクタの原理}

MCFを用いた伝送において，FI/FOデバイスと共に，

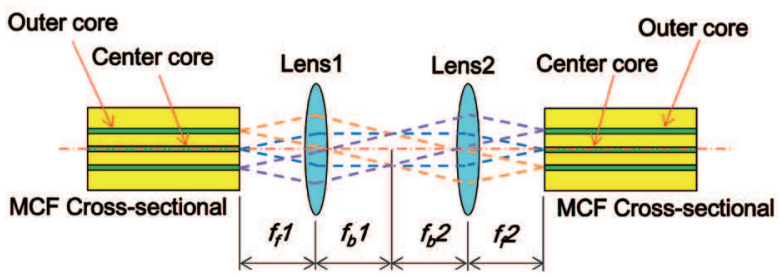

Fig. 5 Schematic diagram of the coupling between MCF's by lens optics.

MCF同士を接続する技術も重要である。その接続方式 の一例として，既存のSMFと同様にフィジカルコンタク 卜 $(\mathrm{PC})$ 接続によるMCFコネクタが検討されている ${ }^{8,9)}$. 球面研磨条件の頂点ズレ, 引き込み量, 曲率半径Rを制 御することで中心以外に外周コアが存在するMCFで あってもPC接続が可能であることが報告されてい る ${ }^{10)}$. しかし，これらはいずれも7コア程度のMCFで検 討されたものであり，将来コア数が拡大した場合にすべ てのコアでPC接続できるかは検討が必要となる。コア 数やコアピッチに依存しない方式として2.1項にて説明 した単レンズを用いた空間結合系にてMCF同士を結合 させることが出来る．Fig. 5のように，外周コアのコリ メートビームが交差するレンズ後側焦点を中心として対 称の光学系を配置すれば1:1の空間結合が実現される.

本原理により，MCFとレンズを一体化したMCFコリ メー夕を対向させる着脱構造を設けることでコネクタ接 続が可能となる.

$$
\begin{gathered}
\text { 3.レンズ結合によるファンイン/ファンアウト } \\
\text { デバイス }
\end{gathered}
$$

\section{1 ファンイン/ファンアウトデバイス設計}

FI/FOデバイスの概略構成をFig. 6に示す. MCFコアは レンズの前側焦点位置ffに配置されることで，ビーム ウェスト距離 $X$ ’とビームウェスト径 $\omega$ は 1 枚薄肉レンズ

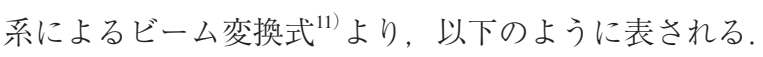

$$
\begin{gathered}
X^{\prime}=f-\frac{f^{2}(f+X)}{\alpha^{2}+(f+X)^{2}} \\
\omega^{\prime}=\frac{\omega_{0} f}{\sqrt{\alpha^{2}+(f+X)^{2}}}
\end{gathered}
$$

$\omega_{0}$ はMCFのモードフィールド径(MFD)である。ただし $\alpha=\pi \omega_{0}{ }^{2} /(4 \lambda)$ であり，入は波長を表す.

$X^{\prime}$ がビームウェスト最遠 $\left(X_{m}\right)$, ビームウェスト径 $\omega$ 'が 最小 $\left(\omega_{m}\right)$ となる条件は (1) 式が極值をとるとき, すなわ ち(1)の微分が0となる時である. このことから次式を得る.

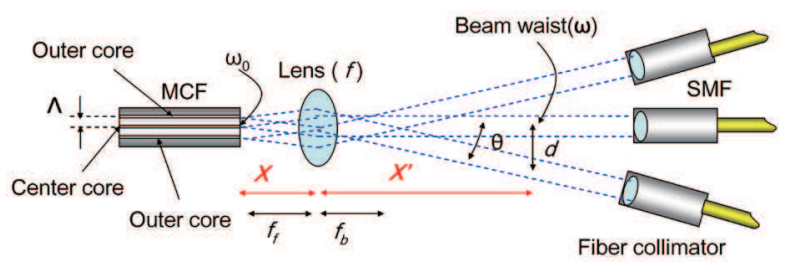

Fig. 6 Schematic configuration of FI / FO device. 


$$
\begin{aligned}
& X_{m}=f+\frac{f^{2}}{2 \alpha} \\
& \omega_{m}=\frac{\omega_{0} f}{\sqrt{2} \alpha}
\end{aligned}
$$

Fig. 6の関係から (5)（6）の関係が成り立つ.

$$
\tan \theta=\frac{\Lambda}{f}
$$

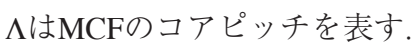

$$
d=\left(X^{\prime}-f\right) \tan \theta
$$

（5），(6) および(3)からビームを最大分離できる距離 $\left(d_{m}\right)$ は次式により導かれる.

$$
d_{m}=\frac{\Lambda f}{\sqrt{2} \alpha}
$$

$\mathrm{FI} / \mathrm{FO}$ デバイスは, コリメートビームの最大分離距離 $X^{\prime}$ とデバイスの全長を考慮してレンズ焦点距離 $\mathrm{f}=2 \mathrm{~mm}$ 前 後が適当として設計した。

次に結合効率の検討結果を示す。実際のMCFコア MFDは8〜11 $\mu \mathrm{m}$ 程度が多く ${ }^{12,13)}$, Table 1 にMFD = $11 \mu \mathrm{m}$, Table 2 に MFD $=8 \mu \mathrm{m}$ の場合の結合効率計算結果を示 す. 両方ともSMFコアのMFDは $\phi 10.5 \mu \mathrm{m}$ し, MCFコ アピッチ $45 \mu \mathrm{m}$, 波長は $1550 \mathrm{~nm}$ としいる. 中心コア と外周コア間の損失差は無く, MFDのミスマッチによ る損失差があるという結果が得られた。ささらに内部光学

Table 1 Coupling efficiency between MCF and SMF (MFD of MCF: $11 \mu \mathrm{m}$ ).

\begin{tabular}{ll}
\hline Center core & $0.04 \mathrm{~dB}$ \\
\hline Outer core & $0.04 \mathrm{~dB}$ \\
\hline
\end{tabular}

Table 2 Coupling efficiency between MCF and SMF (MFD of MCF: $8 \mu \mathrm{m}$ ).

\begin{tabular}{ll}
\hline Center core & $0.21 \mathrm{~dB}$ \\
\hline Outer core & $0.21 \mathrm{~dB}$ \\
\hline
\end{tabular}

Table 3 Calculated reflection loss of internal optical parts.

\begin{tabular}{cc}
\hline Center core & $0.05 \mathrm{~dB}$ \\
\hline Outer core & $0.07 \mathrm{~dB}$ \\
\hline
\end{tabular}

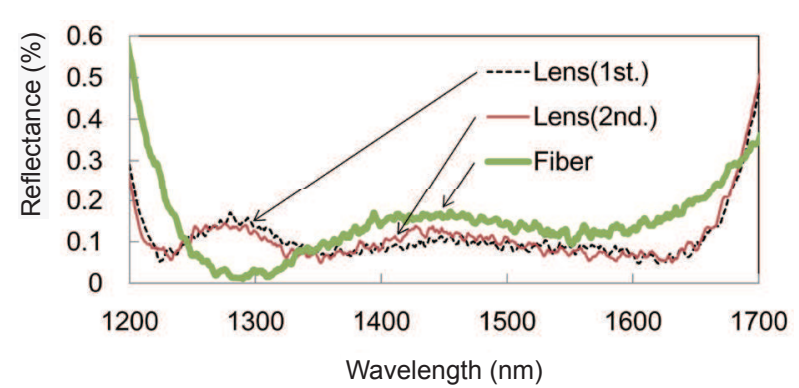

Fig. 7 Example of measured return loss characteristics of AR coating for lenses and fiber.
部品の空気との境界での反射の影響による損失を計算し た結果をTable 3 に示す。但し, 光学部品表面は反射防止 膜が施されており，その反射率はFig. 7に示すように広 帯域にわたって0.2\%以下，透過損失に換算すると $0.01 \mathrm{~dB}$ 以下であるとし，損失に寄与する面は，ファイバ端面， レンズ端面と光路変換のためのプリズム端面の計8面と している。これらの結果より，デバイスの挿入損失設計 值はMCFのMFD = $11 \mu \mathrm{m}$ の場合 $0.1 \mathrm{~dB}$ 以下, $\mathrm{MFD}=8 \mu \mathrm{m}$ の場合でも $0.3 \mathrm{~dB}$ 以下ということになる。構造は，ファ イバとレンズを一体化してコリメータとする方式を採用 した。コリメータ技術は, 従来のSMFを用いたデバイス において一般的に使用されている。サイズは $\phi 40 \mathrm{~mm} \times 62 \mathrm{~mm}$ としている.

\section{2 デバイスの試作評価結果}

空間光学系は様々な条件のMCFにも対応できるが, 試作したデバイスは7コア，コアピッチ45 $\mu \mathrm{m}$, コア径 $10 \mu \mathrm{m}$ MCFを使用した。試作したFI/FOデバイスを Fig. 8，デバイス評価の測定系をFig. 9, 測定結果を Fig. 10に示す。 クロストークを評価する都合上, FI/FO デバイスはMCFにて直接接続された状態で試作・評価 を行った。挿入損失は2台が接続された状態で最小 $0.4 \mathrm{~dB}$ ，最大 $1.2 \mathrm{~dB}$ 以下となり，1台あたりのデバイス損 失は $0.6 \mathrm{~dB}$ 以下と推定できる。偏光依存損失 $(\mathrm{PDL})$ は $0.1 \mathrm{~dB}$ 以下，クロストークは $55 \mathrm{~dB}$ 以上であった(a)。レ ンズ光学系はレンズの色収差の影響から波長によって焦

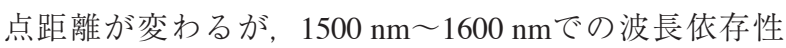
評価の結果は概ねフラットな特性を示しており，問題な いレベルであることを確認した(b).

4. レンズ結合によるマルチコアファイバコネクタ

4.1 マルチコアファイバコネク夕設計

コリメート光同士の結合は, Fig. 4の通り位置ずれに

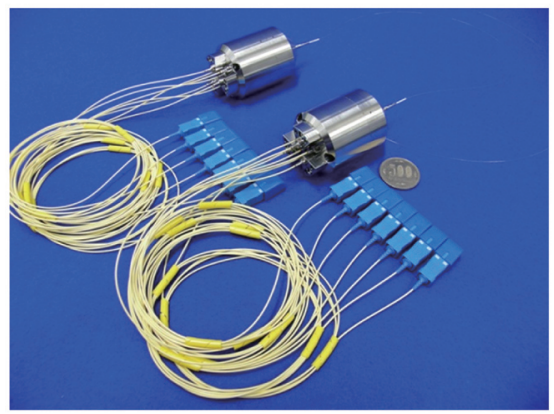

Fig. 8 Photo of the fabricated FI / FO devices.

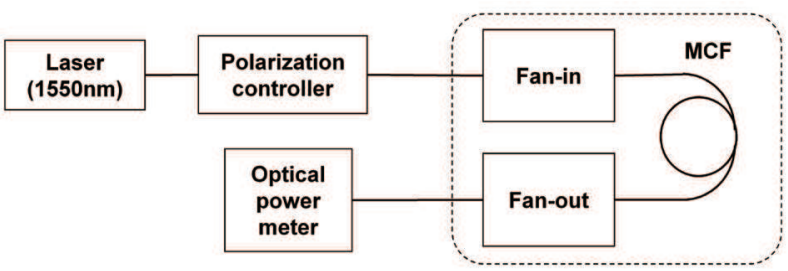

Fig. 9 Measurement setup of insertion loss, PDL, crosstalk, and wavelength dependent loss. 


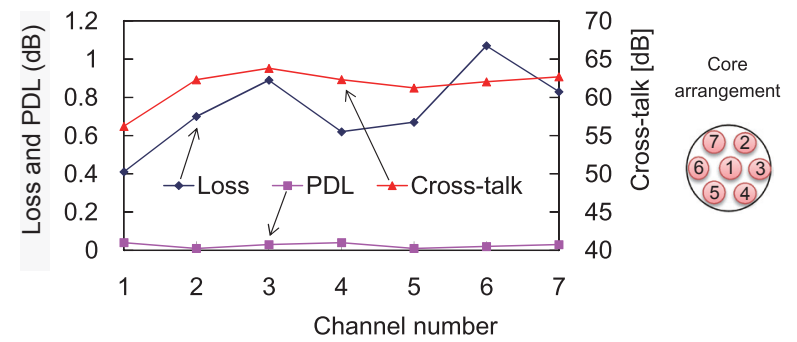

(a)

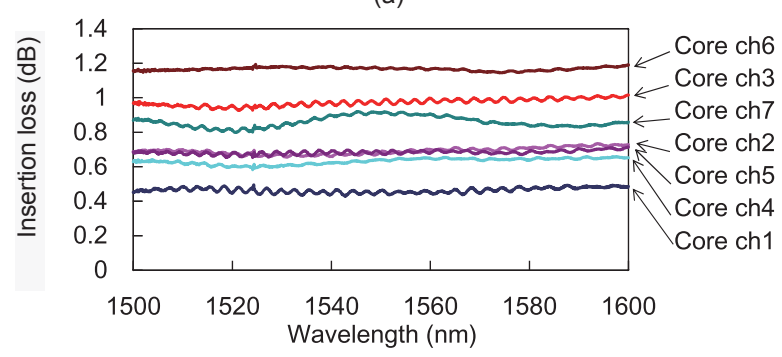

(b)

Fig. 10 Measured optical characteristics of the fabricated module. (a): Insertion loss, cross-talk and PDL. (b): Wavelength dependent loss.

対する損失劣化の許容量は大きい. しかし, 角度ずれに 対しては損失劣化の許容量が小さくなる。Fig. 11 はコア ピッチ $45 \mu \mathrm{m}$ の時のビーム径に対する角度ずれ時損失の 計算結果である。この結果から，ビーム径が小さいほど 許容量を増すが, ビーム径が小さいとレンズ焦点距離は 短くなるため, 実装性を考慮してビーム径は297 $\mu \mathrm{m}$ と した，MCF同士の結合効率については，MFDは1:1とな るため, 理論上結合損失は生じない。ファイバ端面及び 光学部品の端面反射による損失はTable 3に示したCenter coreと同じになるため, 結合損失の設計值は $0.1 \mathrm{~dB}$ 以下 となる。

着脱構造部の構成は, Fig. 12のようにMCFとレンズを 一体化するコリメータとした，MCF中心コアとレンズ の主軸が同軸上にあれば機械精度だけでの位置合わせが

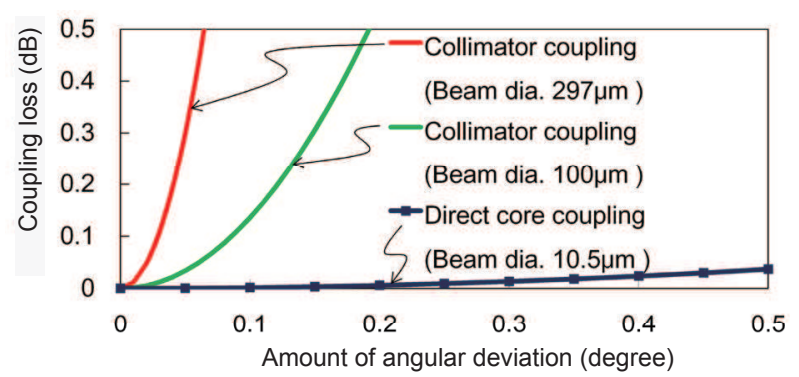

Fig. 11 Comparison of tolerance of the coupling loss to the angular deviation between direct fiber coupling (MDF: $10.5 \mu \mathrm{m}$ ) and lens coupling.

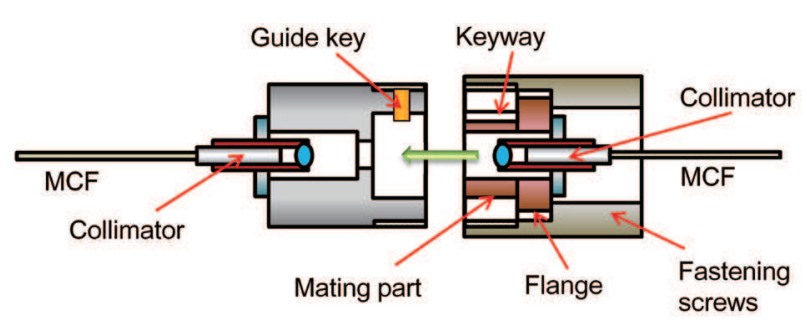

Fig. 12 Schematic of the MCF connector structure.
可能であるが，実際にはMCFコアの偏心，レンズ主軸 の偏心，及び反射を考慮してMCF端面を斜め研磨した 場合の光軸のオフセットの影響があるため, コリメータ はコネクタの軸に対して位置と角度の調整固定を行える 構造としている。 また，着脱時に角度ずれが起きないよ うフランジ部を設け，そのフランジ面を加圧固定するこ とで角度ずれが影響しない構造とした，位置ずれに対し てのクリアランスは最大 $20 \mu \mathrm{m} あ り ，$ 着脱を容易にして いる.この構造により, 通常のSMFコネクタのフェ ルール外径公差 $\pm 0.5 \mu \mathrm{m}$ に比べて格段に緩い寸法公差で 設計でき，サイズは $\phi 19 \mathrm{~mm} \times 35 \mathrm{~mm}$ とした。

\section{2 マルチコアファイバコネクタの試作評価}

Fig. 13に試作したコネクタ外観を示す，MCFはFI/FO デバイスと同じ仕様のものを使用した。評価のための測 定系をFig. 14，測定結果をFig. 15に示す。試作時の結合 損失は最小 $0.1 \mathrm{~dB}$, 最大 $0.86 \mathrm{~dB}$ となった $(\mathrm{a}) .3$ 回着脱時 の最大損失はチャンネル3にて $1.0 \mathrm{~dB}$, 着脱再現性は $0.75 \mathrm{~dB}(\mathrm{~b})$. PDLは最大 $0.6 \mathrm{~dB}$ となった。結合損失とPDL が大きくなった主要因は，コア配置を適切に設定しな かった為コアピッチずれが発生して損失となったと考え ている，初期の状態で結合ずれが起きているため，着脱 再現性も悪くなったと考えられる.

接続損失はコア配置の見直しにより全コアを中心コア 接続損失と同程度にできることが可能であり，同時に着 脱再現性, PDLも改善可能である.

\section{5. 今後の展開}

MCFを使用して光伝送を行う為にはMCF各コアへ信 号の入出力，既存デバイス及びネットワークに接続する ためにFI/FOデバイスは必須である。7コア MCF-16.8 km

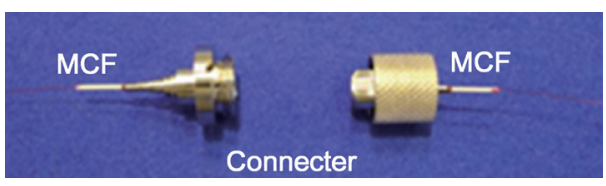

(a)

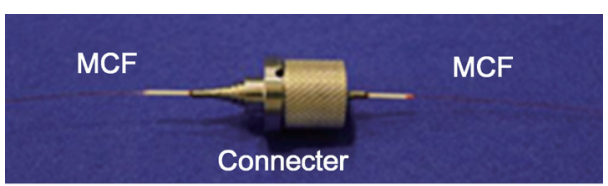

(b)

Fig. 13 Photo of the prototype connector: disconnected (a), and connected (b).

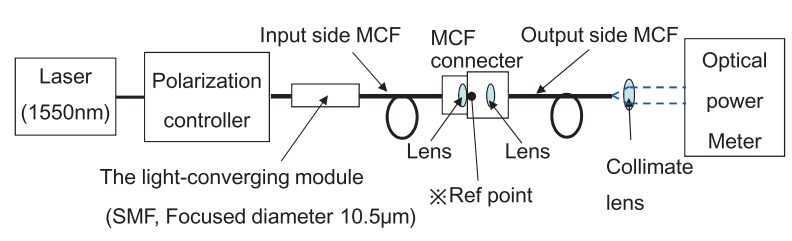

Fig. 14 Measurement setup of insertion loss, PDL, and reproducibility of coupling loss for connecting and disconnecting. 


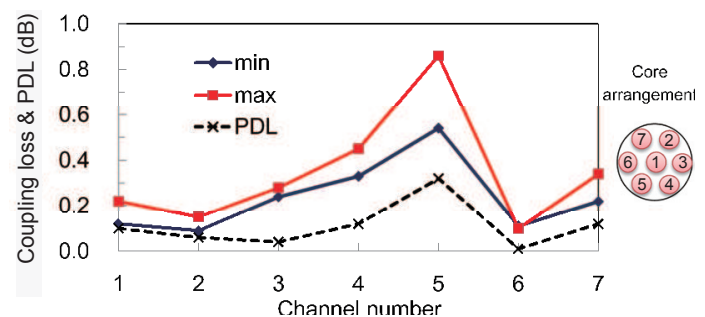

(a)

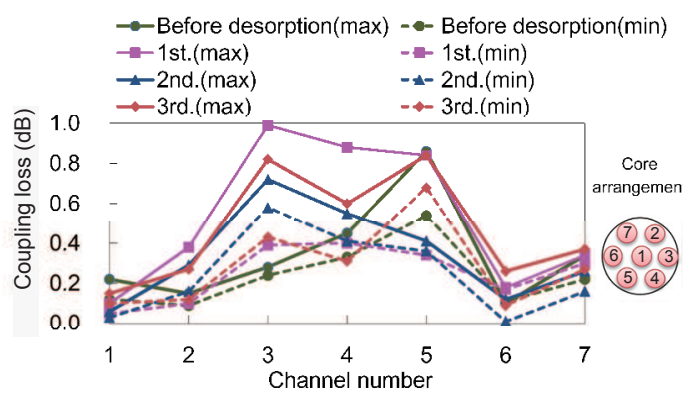

(h)

Fig. 15 Measured optical characteristics of the connecter. (a): coupling loss and PDL as manufactured. (b): polarization dependence of coupling loss after connecting and disconnecting three times.

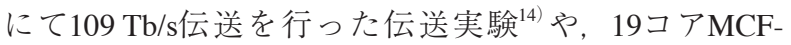

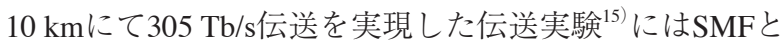
の接続に本稿で述べた空間結合によるFI/FO技術が用い られていたが, 原理実験器であることから調整機構を有 しており $\phi 300 \times 400 \mathrm{~mm}$ 程度というサイズであった。今 回試作したFI/FOデバイスはこれに対して体積比 $1 / 360$ の 小型デバイスで実現しており，より実用に近い伝送系の 構成が可能である。 また, 長距離伝送実験を行う際に複 数のMCFをコネクタにより簡便に接続出来れば多様な 伝送実験の構成が可能となる。今後本MCF用FI/FOおよ びコネクタを用いた伝送実験によってその適用性を検証 していきたい。

\section{6. まとめ}

空間結合系にて低損失なFI/FOデバイスとコネクタ構 造を実現できることを確認した。今後は更なる低損失, 小型化の検討を進め，実用に耐えうる性能を実現するこ とが課題である。現在7コアMCFを主に検討している が，MCF自体は更なる通信容量拡大の為12コア，19コ
アについても既に実現されており，空間光学系を用いた 接続技術は今後の更なるコア数の増加にも対応できる技 術として期待している。また，空間光学系は光路中に接 着剤等の有機物が介在しないため，ハイパワー光入力へ の対応や高リターンロスを必要とする用途に適したデバ イスとして重要であると考えている。

\section{謝 辞}

本研究は, (独) 情報通信研究機構の高度通信・放送研 究開発委託研究/革新的光通信インフラの研究開発の一 環としてなされたものである。

\section{参考文献}

1) T. Morioka: Technical Digest of Opto Electronics And Communications Conference Hong Kong, July 2009, Paper FT4.

2) H. Takara, A. Sano, T. Kobayashi, H. Kubota, H. Kawakami, A. Matsuura, Y. Miyamoto, Y. Abe, H. Ono, K. Shikama, et al.: Proc. European Conference Optical Communication Amsterdam, September 2012, Paper Th.3.C.1

3) H. Takahashi, T. Tsuritani, E. L. T. de Gabory, T. Ito, W. R. Peng, K. Igarashi, K. Takeshima, Y. Kawaguchi, I. Morita, Y. Tsuchida, et al.: Proc. European Conference Optical Communication Amsterdam, September 2012, Paper Th.3.C.3.

4）佐々木雄佑，竹永勝宏，荒川葉子，谷川庄二，松尾昌一郎， 齊藤 晋聖，小柴 正則：電子情報通信学会ソサイエティ大 会 B-10-27 (2011).

5) 今村勝徳, 武笠和則, 杉崎隆一：電子情報通信学会ソサ イエティ大会 B-13-36 (2011).

6）島川修，佐野知巳，井上 享：電子情報通信学会ソサイエ ティ大会 B-13-7 (2012) .

7) 渡辺 健吾, 斎藤 恒聡, 今村勝徳, 椎野 雅人：電子情報通 信学会ソサイエティ大会 B-10-9 (2012)

8 ）蟹江智彦，島川修，井上亨：電子情報通信学会総合大会 岡山大学 B-13-50 (2012).

9）境目賢義，長瀬亮，渡辺 健吾，斎藤 恒聡：電子情報通信 学会ソサイエティ大会 B-13-9 (2012).

10）鹿間光太, 阿部 宜輝, 柳 秀一, 高橋哲夫：電子情報通信 学会ソサイエティ大会 C-3-80 (2012).

11) 河野健治：光結合系の基礎と応用(現代工学社, 1991) p.166.

12) 五藤 幸弘, 中島 和秀, 冨田茂: 電子情報通信学会ソサイ エティ大会 B-13-35 (2011).

13）小柴 正則：電子情報通信学会ソサイエティ大会 BCI-2-1 (2011).

14) J. Sakaguchi, Y. Awaji, N. Wada, A. Kanno, T. Kawanishi, T. Hayashi, T. Taru, T. Kobayashi, and M. Watanabe: Technical Digest of OFC/NFOEC Los Angeles, March 2011, PDPB6.

15) J. Sakaguchi, B. J. Puttnam, W. Klaus, Y. Awaji, N. Wada, A. Kanno, T. Kawanishi, K. Imamura, H. Inaba, K. Mukasa, et al.: Technical Digest of OFC/NFOEC Los Angeles, March 2012, PDP5C.1.

\section{レーザーワード}

コリメート光 (collimated beam)

レーザー光は単色性に優れているため指向性が良く 空間を長距離伝搬してもビーム径が変化せず平行のまま 伝搬させることが可能である。このような平行な光束を 「コリメート光」と呼ぶ. 単一モード光ファイバ中を進む レーザー光は内部全反射を繰り返して伝搬するため, 空 間へ出射すると出射角を有する拡散ビームになる。その
ためレンズ等の屈折を用いてコリメート光を発生させる 方法が一般的に用いられている。コリメート光を用いる ことで，空間光路中に様々な機能素子を入れたり，ミ ラーなどにより光路を曲げることが可能となりレーザー 光を自在に操作することが可能となる。 (小林哲也) 